\title{
Congenital Unilateral microtia in a neonate of hypothyroid, hypertensive and diabetic mother $-\mathbf{a}$ rare case report
}

\author{
Dr. Parul Sinha, Dr. Iti. Chowdhary, Dr. (Prof) Hem Prabha Gupta, Dr. \\ (Prof)Uma Gupta, Dr.(Prof)Kumkum Srivastava \\ Assistant Professor (Obstetrics \& Gynecology) Era's Lucknow Medical College, Lucknow \\ Junior Resident (Obstetrics \& Gynaecology) Era's Lucknow Medical College, Lucknow \\ Professor (Obstetrics \& Gynaecology) Era's Lucknow Medical College, Lucknow \\ Professor (Obstetrics \& Gynaecology) Era's Lucknow Medical College, Lucknow \\ Professor \& Head of the Dept. (Obstetrics \& Gynecology) Era's Lucknow Medical College, Lucknow
}

\begin{abstract}
:
Introduction Anotia is a condition when ears are completely absent while microtia is a congenital anomaly of the face in which the ears are malformed since birth and it ranges in severity from mild structural abnormalities to complete absence of the ear and its parts.

Case presentation We report a case of unilateral microtia in a newborn of hypothyroid mother. The mother had severe preeclampsia and her LSCS was done for uncontrolled blood pressure. No other apparent congenital anomaly was detected. The family history of the patient showed that both patient and her father have deafness. Their BERA (brain evoked response audiometry) test showed severe hearing loss on right side and moderate hearing loss on left side.
\end{abstract}

Conclusion: Therefore in this case we found conductive deafness in 3 generations.

Keywords: Microtia; anotia; congenital defect; hereditary; ear deformity

\section{Introduction}

Anotia is a condition when ears are completely absent while microtia is a congenital anomaly of the face in which the ears are malformed since birth which ranges in severity from mild structural abnormalities to complete absence of the ear and its parts. It occurs as an isolated birth defects or as a part of spectrum of anomalies or as a syndrome. This may happen as a part of first brachial arch syndrome or in isolation too. The prevalence is considered to be higher in Hispanics, Asians, Native Americans and Andeans. The aetiology of microtia and causes of congenital anomaly is not clearly defined and explained till now; there is wide variability in prevalence that is poorly understood too. Strong evidences support the role of environmental and genetic causes of microtia. Here we are discussing a case of microtia on one side and normal ear on other side in a newborn.

\section{Case report}

A rare case of microtia was observed in gynaecology and obstetrics department of Era's Lucknow medical college Lucknow. The patient $\mathrm{G}_{2} \mathrm{P}_{0+1} \mathrm{~L}_{0}$ known case of hypothyroidism on tablet Eltroxin 25 microgram presented in outpatient department with the chief complaint of labour pains for 2 hours following 38 weeks 2 days of pregnancy. Her per abdomen findings were uterus was term size, lie was longitudinal, cephalic presentation, FHS was $130 \mathrm{bpm}$, regular at right spino umbilical line. Patient was having 2 moderate contractions in 10 minutes. Her per vaginum findings were, cervical os was $2 \mathrm{~cm}$ dilated, cervix was $40-50 \%$ effaced, head at ' -3 ' station, membranes were present. Pelvis was adequate. Her vitals at time of admission were pulse-92/min, RR -20/min, B.P.-170/130 mm of $\mathrm{Hg}$ for which $5 \mathrm{mg}$ tab nifedipine was given and her B.P. reduced to $160 / 120 \mathrm{~mm}$ of $\mathrm{Hg}$, urine protein was $3+++$. LFT was normal and coagulation profile was normal, platelet count was 1.9 lakh / cumm. Since her B.P. was not being controlled and Bishop scoring was poor she was shifted for emergency LSCS. She delivered a female baby by vertex presentation weighing $2.03 \mathrm{~kg}$. Baby cried immediately after birth .On examination of the baby it was found that the baby had malformed right ear and left ear was normal .The baby was handed over to the paediatrician for proper examination and investigation. Length of the baby was $49 \mathrm{~cm}$ and head circumference was $36 \mathrm{~cm}$. There was no other dysmorphism and other examinations were normal. It was diagnosed as a case of congenital unilateral microtia of right ear with normal left ear (figure-1). There was no other apparent congenital anomaly detected. The family history of the patient showed that both patient and her father have deafness. Their BERA (brain evoked response audiometry) test showed severe hearing loss on right side and moderate hearing loss on left side. Therefore in this case we found conductive deafness in 3 generations. There was no history of antenatal fever, exposure to drugs, and radiation during the antenatal period. The child developed icterus on $3^{\text {rd }}$ day of life which 
remained for 10 days. There was no evidence of AB0Rh incompatibility, G6PD deficiency and the baby was kept on phototherapy for 10 days. Ultrasound of abdomen and neck of the baby was normal. Renal function tests were normal. Chromosomal analysis of the baby revealed XX karyotype. Baby's thyroid level was normal.

\section{Discussion}

Microtia and anotia can be grouped into four types according to the level of affliction1.Type 1: the external ear is small and the auricle retains most of its normal structure. The external auditory meatus is usually present. Type 2: the external ear is moderately anomalous. The auricle can be hook- shaped, S- shaped, or question mark shaped in appearance. Type 3: the external ear is a rudimentary soft tissue structure with no cartilage; the auricle does not have a normal appearance. Type 4: Anotia; all external ear structures are absent. Our patient falls into the third category. It can occur unilaterally (79-93\% of cases) or bilaterally; in unilateral cases the right ear is more often affected ${ }^{(2)}$ as in our case. There are few published studies on microtia - anotia frequency. The birth prevalence estimates vary greatly among countries ranging from 0.8 to 17.4 per $10,000{ }^{(3)}$. Anotia accounts for $13-22 \%$ of all cases of microtia and anotia combined ${ }^{(4)}$. It can be an isolated finding or it may be associated with goldenhar syndrome (most severe manifestation of occulo-auriculo-vertebral spectrum). Treacher Collis syndrome, Oromandibulo-facial dysostosis, Meir Gorlin syndrome, Thalidomide embryopathy ${ }^{(3)}$, Diabetic Embryopathy ${ }^{(5)}$, Holoprosencephaly, Fryns syndrome etc. ${ }^{(6)}$. Inheritance can be multifactorial or autosomal dominant. Preauricular pits and sinuses, and a combination of pits, preauricular appendages(skin tags), cupping deformity, and deafness are all hereditary dominant ${ }^{(7)}$, both dominant and recessive characteristics have been revealed in deafness associated with several auricular abnormalities ${ }^{(8)}$.

\section{Conclusion}

In our case we did not find any associated feature suggesting any syndrome but there was a family history of deafness. Mother was a known case of hypothyroidism and developed pregnancy induced hypertension. There was a history of deafness in three generations. There was genetic component to the disease which could have been detected by doing chromosomal analysis of the baby and its parents. But this was not done as the patient did not give consent. We also make the inference that some vascular insult may have occurred in early weeks of gestation resulting in this type of anomaly.

\section{Consent}

Written informed consent was obtained from the patient for publication of this case report and accompanying image. A copy of the written consent is available for review by the Editor-in-Chief of this journal.

Competing interests: 'The author(s) declare that they have no competing interests'.

\section{Acknowledgements} their neonate.

We thank the patient's family for allowing to do the various tests (BERA) and to make a case report on

\section{References:}

[1]. Meurman Y. Congenital microtia and metal atresia. Arch. Otolaryngology. 1957; 66: 443.

[2]. Sadler T. Langmans Medical Embryology, 8th Edition. Baltimore, U.S.A; Lippincott Williams and Wilkins, 1997 ; 391.

[3]. Mastroiacovo P, Corchia C., Botto L.D.Epidemiology and genetics of microtia and anotia: A registry based study on over an million births, Ann Genet. 1989; 32: 52-54.

[4]. Harris J, Kallen B, Robert E. The Epidemiology of anotia and microtia.J Med Genet.1996; 36; 809-813.

[5]. Rasore-Quartino A, Rovei S. A case of thalidomide anotia. JAMA 1966; 195: 695-696.

[6]. Slavotinek AM.Fryns Syndrome: a review of the phenotype and diagnostic guidelines. Am J Med Genet A .2004;124 A;427-433

[7]. Wildervanck, L.S.: Hereditary malformation of the ear in three generations: marginal pits, Otolaryngol. 1962;54:55

[8]. Konigsmark BW.Hereditary deafness in man. New Engl J Med. 1969; 281:713. 
Figure 1-unilateral microtia

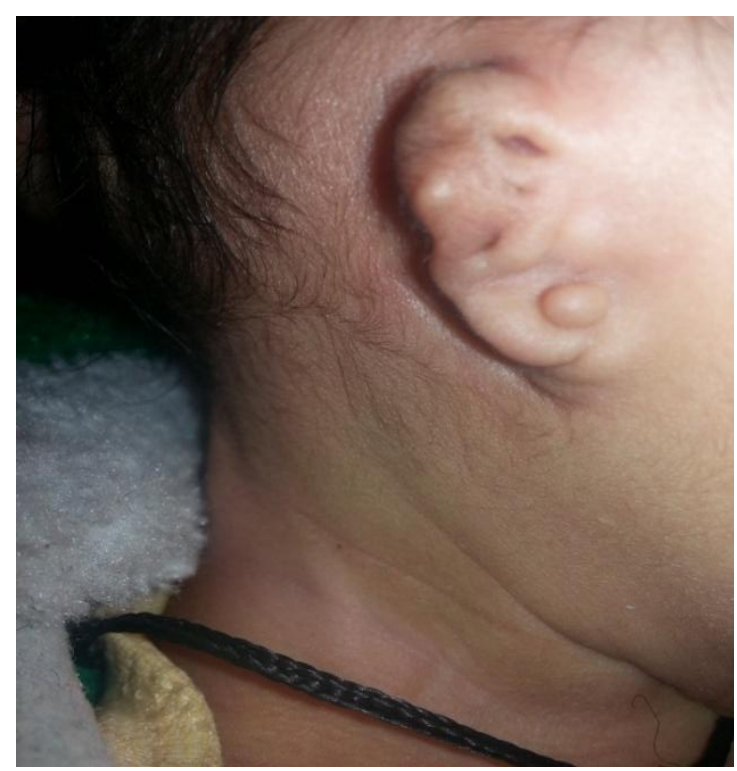

